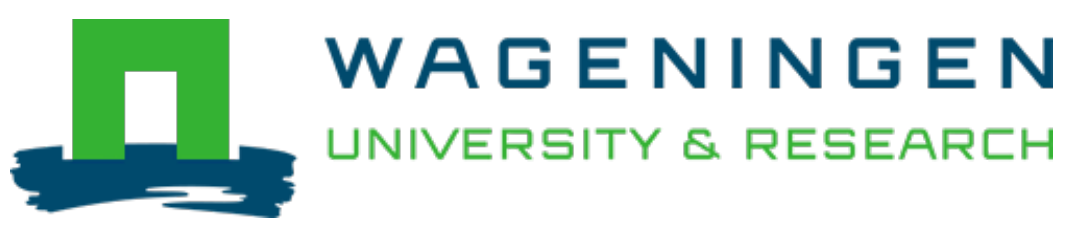

\title{
Consumption Habits and Innovation Potential of Mung Bean Foods in Hisar District of Haryana State, India
}

\author{
Ecology of Food and Nutrition \\ Dahiya, P.K.; Linnemann, A.R.; Nout, M.J.R.; Boekel, M.A.J.S.; Khetarpaul, N.K. et al \\ https://doi.org/10.1080/03670244.2013.807809
}

This publication is made publicly available in the institutional repository of Wageningen University and Research, under the terms of article $25 \mathrm{fa}$ of the Dutch Copyright Act, also known as the Amendment Taverne. This has been done with explicit consent by the author.

Article 25 fa states that the author of a short scientific work funded either wholly or partially by Dutch public funds is entitled to make that work publicly available for no consideration following a reasonable period of time after the work was first published, provided that clear reference is made to the source of the first publication of the work.

This publication is distributed under The Association of Universities in the Netherlands (VSNU) 'Article $25 \mathrm{fa}$ implementation' project. In this project research outputs of researchers employed by Dutch Universities that comply with the legal requirements of Article $25 \mathrm{fa}$ of the Dutch Copyright Act are distributed online and free of cost or other barriers in institutional repositories. Research outputs are distributed six months after their first online publication in the original published version and with proper attribution to the source of the original publication.

You are permitted to download and use the publication for personal purposes. All rights remain with the author(s) and / or copyright owner(s) of this work. Any use of the publication or parts of it other than authorised under article $25 \mathrm{fa}$ of the Dutch Copyright act is prohibited. Wageningen University \& Research and the author(s) of this publication shall not be held responsible or liable for any damages resulting from your (re)use of this publication.

For questions regarding the public availability of this publication please contact openscience.library@wur.nl 


\title{
Consumption Habits and Innovation Potential of Mung Bean Foods in Hisar District of Haryana State, India
}

\author{
PRADEEP K. DAHIYA \\ Center of Food Science and Technology and Department of Foods and Nutrition, CCS \\ Haryana Agricultural University, Hisar, Haryana, India; and Product Design and Quality \\ Management Group and Laboratory of Food Microbiology, Wageningen University, \\ Wageningen, The Netherlands \\ ANITA R. LINNEMANN \\ Product Design and Quality Management Group, Wageningen University, Wageningen, \\ The Netherlands \\ MARTINUS J. R. NOUT \\ Laboratory of Food Microbiology, Wageningen University, Wageningen, \\ The Netherlands \\ MARTINUS A. J. S. VAN BOEKEL \\ Product Design and Quality Management Group, Wageningen University, Wageningen, \\ The Netherlands \\ NEELAM K. KHETARPAUL \\ Department of Foods and Nutrition, CCS Haryana Agricultural University, \\ Hisar, Haryana, India \\ RAJ B. GREWAL \\ Center of Food Science and Technology, CCS Haryana Agricultural University, \\ Hisar, Haryana, India
}

Consumption habits for mung bean foods were assessed by the free word association method and interview techniques. Four groups of closely related products and perceived quality were revealed. The largest group comprised sweets and snacks, which were associated with unhealthiness, expensiveness and sensory liking. Another group consisted of split dhals associated with convenience and healthiness. It appeared that under different circumstances food

Address correspondence to Rob M. J. Nout, Laboratory of Food Microbiology, P. O. Box 17, 6700 AA Wageningen, The Netherlands. E-mail: rob.nout@wur.nl 
choices vary and are influenced more by socioeconomic restrictions then by consumer perception and preferences. Scenario analysis based on consumer perception, preferences, practices and nutritional value of products revealed dhals as the most promising food for innovation.

KEYWORDS consumer knowledge, consumer preferences, dhals, dietary practices, food innovation and convenience, halwa, Indian traditional food products, nutrition, quality perception

Malnutrition is a major concern in India; the number of malnourished children, for instance, is amongst the highest in the world (Pathak and Singh 2011). Combating malnutrition through upgrading indigenous foods and dietary diversification is a promising approach (Ruel and Levin 2002). Indigenous foods are culturally accepted, ecologically adapted and easily accessible. However, for technological improvements to take full advantage of their nutritional potential, product development should be consumer oriented to ensure acceptance (Linnemann et al. 2006).

Consumer choices for food are influenced by the perception of food quality, food preferences, food awareness, accessibility and affordability (Siró et al. 2008). Therefore, it is important to know these factors that influence consumer's choice and their relation with the nutritional potential of a food product. This study aims to identify these factors in three different aspects of food consumption, namely perception, preferences and consumption practices, and their interrelation with each other, as well as with the nutritional potential of food products.

Perception is understood as a psychological phenomenon by virtue of which an individual understands sensory information (Giampieri-Deutsch 2012), whereas preferences are consumer's choices in the absence of socioeconomic constraints. Different aspects of food choices and consumption need different approaches for data collection. This study was formulated using both quantitative and qualitative approaches through the combination of structured interviewing, participant observation, focus group discussions and the free word association methodology. Focus group discussions and participant observation yield the diversity of food consumption patterns. The free word association methodology is one of the commonly used qualitative techniques for assessing one's beliefs and attitudes (van Kleef et al. 2005; Guerrero et al. 2010). This method will reveal the conscious factors governing consumer choices in terms of perception, whereas interview techniques will help in understanding the unconscious concepts and associations with foods.

In the present study, mung bean (Vigna radiata (L.) R. Wilczek) foods in northern India were used as they are an important component in the diet, rich in minerals and proteins (Dahiya et al. 2013b) and culturally accepted. 
The present work was part of a bigger project aiming at strengthening the local mung bean food network in India with a view to assist local populations in achieving food sovereignty (Quaye et al. 2009). Although overall data on production and consumption of mung beans in India were published (Khetarpaul and Khetarpaul 2006), little knowledge is available on the food habits and preferences relating to mung bean.

Mung bean is known in many forms in terms of varieties and products with diverse consumption and processing patterns. Nutritionally it is recognized as one of the potential legumes for the South Asian population (Yang and Tsou 1998). Diversity in mung bean products gives consumers an assortment from which they can select their preferred food consciously and unconsciously in different situations and according to sensory liking, accessibility, affordability and ease of processing.

This study aimed to understand different aspects of mung bean consumption to conceptualise its food consumption pattern with its associated influencing factors, to enable a critical evaluation of the innovation potential for improvement in terms of nutritional contribution to malnourished people.

\section{METHODS}

\section{Research Area}

The research was conducted in the Hisar district of Haryana state in northern India. Haryana is an agricultural state and one of the largest mung bean producers in India. Hisar was selected as the research area as this district has the highest production of mung bean in Haryana state. A multi-stage sampling procedure was used for the selection of blocks in districts, villages and respondents. Hisar city was selected to include urban consumers of mung bean. For rural consumers two blocks, namely Hisar-1 and Barwala, were selected. From each block one village was selected, Dhiktana village from Barwala block and Mangali village from Hisar-1 block.

\section{Demographic Details of the Respondents}

The 152 respondents in our study were from Hisar city (50\%) and both villages (50\%), included 50\% males and 50\% females of different ages and economic background. Sample size was set according to Dagnelie (Dagnelie 1998) as described by Chadare and colleagues (2008).

Amongst the respondents 19.1, 25.0, 38.8 and 17.1\% were aged from 8-19, 20-35, 36-50 and above 50 years, respectively. Out of these $71.1 \%$ were married. In terms of education status 30.9\% were uneducated, $13.2 \%$ had a primary level school education, $20.4 \%$ had a secondary level school education and $13.8 \%$ had a highschool level education, whereas $16.4 \%$ were graduates and 5.3\% were post graduates. The occupations included farmers (15.2\%), house wives (30.3\%), civil servants (20.3\%), businessmen (10.5\%) 
and school students (23.7\%). The annual income of the respondents. in Indian rupees ( 1 US $\$=54.5$ Indian rupees), ranged from 0-2000 (5.3\%), 2001-5000 (18.4\%), 5001-10000 (38.2\%), 10001-15000 (25.0\%) and above $15001(13.1 \%)$.

\section{Focus Group Discussions}

To take stock of the different mung bean varieties produced and processed and the mung bean based foods consumed by the population, focus group discussions with 10-12 participants were conducted in each rural and urban area. Focus groups consisted of at least one commercial and one household processor of mung bean, along with female, male, children and elderly people as consumers of mung bean. Three focus group discussions were held with 10-12 participants in the respective urban and rural areas.

Group participants were informed about the purpose of the focus group discussion. Participants were asked to freely interact with each other on the given topic. Theme for the focus group discussions was the number and type of mung bean products commonly processed and consumed. Participants were asked to sort products into groups and to identify the main characteristics of each group formed. The probes used for the discussion were household/commercial products and dhals, sweets and snacks. Key points commented about the mung bean products were recorded. During the discussions 14 mung bean products were identified, which were used later in the free word association test. The outcome was also used to validate and develop the interview questionnaire.

\section{Interviews with Structured Questionnaire}

A cross sectional survey of consumers was conducted using a structured questionnaire. The questionnaire was framed into four sections to collect data about consumer knowledge of mung bean products, preferences, quality perception and consumption practices, respectively. Questions were designed to gather both qualitative data through multiple choice questions and quantitative data through open questions. Pre-testing and finalizing of the questionnaire was done on the basis five test interviews and suitable changes were made. The questionnaire was in English, and was translated in the local language (Hindi) or dialect (Haryanvi) when needed during data collection. The objective of this part of the study was explained to each respondent before the interview. Data was taken personally by administering the interview schedule to the respondents.

\section{Free-Word-Association Tests}

All respondents participated individually in this test. The objective of this test was not disclosed at the start of the test to minimize bias. The test started 
with a short discussion about the respondent's food consumption pattern to get the interviewee focused on the topic. Next, the procedure of a free word association test was explained using examples of food products other than mung bean products. The respondents were asked for their opinion of all the 14 mung bean products one by one. The test involved confronting the respondent with the product (the stimulus) and then waiting for the first few verbal responses that came to his/her mind. Each respondent was asked to elicit any number of different words in his own regional language. A maximum of 30 seconds was allowed for responding. The total duration of the test, including discussion and explanation, ranged from 15 to 20 minutes. All the words were recorded.

All elicited words associated with mung bean and its derived products were translated into English. For each product, words with similar meanings were grouped into several categories. This categorization was done manually considering word synonymy. The frequencies in each category were determined by counting the number of respondents who associated those words with mung bean and its derived products. Associated words for different products were compared and merged into ten response categories considering their similar meaning and these were labeled. The response categories included (1) sensory liking or disliking, (2) having a positive or negative health impact, (3) affordability or expensiveness, (4) easy or difficult to get, and (5) easy or difficult to process. Easy to get and easy processing was represented by "convenience" and difficult to get and difficult processing by "inconvenience". Frequency of words used for each response category was calculated for each product.

\section{Statistical Analysis}

Data were analyzed using descriptive statistics (mean, frequencies and percentages). Chi-square was calculated to analyze differences in the consumer perception of quality of mung bean and its derived products. Correspondence analysis was applied to investigate the relationship between mung bean products and response categories (Sourial et al., 2010). All statistical analyses were performed with PASW Statistics (Version 18.0.2) IBM Co. USA.

\section{RESULTS}

\section{Mung Bean Varieties and Derived Food Products}

Hybrid as well as local, traditional mung bean varieties are produced, processed and consumed in the research area. Hybrid mung bean varieties are asha, muskan, and satya. There is no particular name for the local, traditional varieties; people use the word desi (meaning "local") to designate 
them. These varieties have small-sized and bright green colored grains. Consumers are not aware about the varieties used for mung bean products; generally they select a variety with small, round, bright green colored grains, without damaged grains, clean and reasonably priced. However, commercial processors select mung bean varieties according to the product they want to prepare.

With respect to mung bean foods, 14 mung bean products were identified and classified into four groups. The first group consisted of the dhals (i.e., whole dhal, split dhal, dehulled split dhal). Dhals are spiced curries of whole or split legumes, with thick soup-like consistency commonly consumed with cereal products like rice and chapattis (Indian flat bread).

The second group comprised the sweets, which included three products, namely laddu, burfi, and halwa, prepared with dehulled split mung bean by shallow frying the mung bean flour or paste and addition of ghee (clarified butter oil) and sugar. It also included whole laddu, which are round balls of crushed whole grains prepared by shallow frying with ghee.

The third group, the snacks, included namkeen, papad, bhalle, and pakore. Namkeen are deep fried, spiced or salted, dehulled split mung bean grains. Papad is a spiced flat roasted product of dehulled split mung bean. Bhalle are round balls of deep fried, dehulled, fermented mung bean paste, whereas pakore are round or irregular shaped balls of deep fried fresh paste of dehulled or split mung bean with some spices and vegetables.

Wadi, ankurit dhal, and kbichadi each have distinctive characteristics and were grouped as the fourth category of mung bean products. Wadi are irregular shaped, sun dried dumplings of fermented, dehulled mung bean paste, which are cooked as curry with spices and other vegetables. Ankurit dhal are germinated mung bean grains eaten as such or in salads after shallow frying. Khichadi is a thick porridge-like product prepared by cooking split or dehulled grains with white rice.

\section{Consumer Awareness and Preferences}

The data depicting consumer awareness and preferences for mung bean and its derived products is given in table 1 . Our research did not reveal significant differences in preferences between different age groups.

The majority of consumers were familiar with all mung bean products except for one product called whole laddu. It is processed mostly by rural families. The majority of consumers did not know the processing of mung bean products, except for dhals, khichadi, and ankurit dhal. Similarly, consumers had limited knowledge of storage methods for most of the mung bean sweets and snacks. Use of refrigeration as storage method was quite common in case of foods with high moisture content such as dhals, khichadi, and sprouts. Low moisture foods like dehulled laddu, namkeen, and papad were kept at room temperature. 


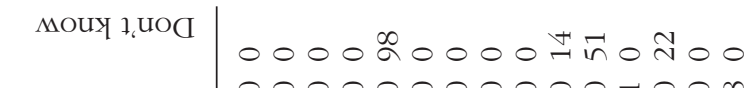

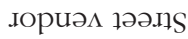

$$
\begin{aligned}
& 00000000008 \overrightarrow{\mathrm{I}} 000 \\
& \text { әреш әшон }
\end{aligned}
$$

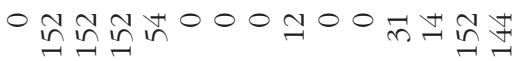

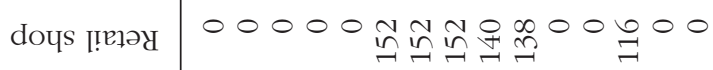

$$
\begin{aligned}
& \mathrm{ON}
\end{aligned}
$$

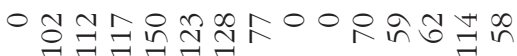

$$
\begin{aligned}
& \text { səג }
\end{aligned}
$$

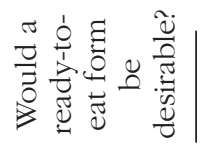

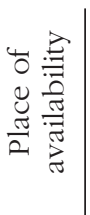

0000 a 0000 iñ

츤 чроष

o 000 Hanm URq.IO

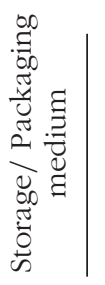

$$
\text { je.Iny }
$$

0000 아이이 0000000

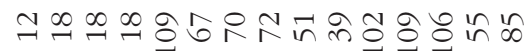

MOUY 1,UOC

oreq Kuung

NO0000000000000

८еq ग!̣se [d

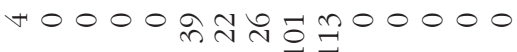

๘!รนวฺก

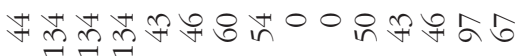

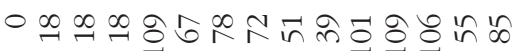

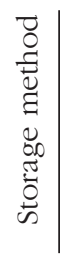

MOUY 1,UOC

ว.IOIS 1, UOC

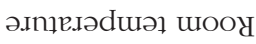

$0000000 m$ n

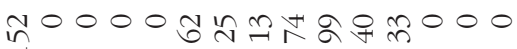

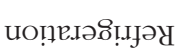

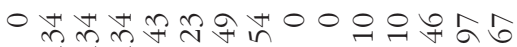

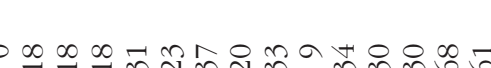

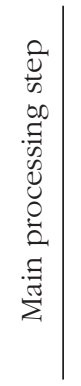

MOUY a, UOC

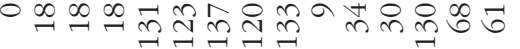

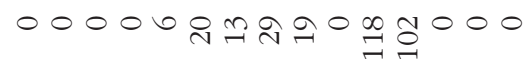

8u! $\mathrm{SI}_{\mathrm{H}}$

8u!YoOJ

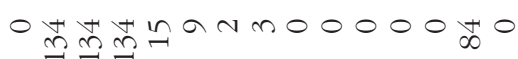

$00000000000000 \pi$

บоำหนฺ̣น.ıว

000000000 m 00000

8u!̣seoy

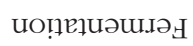

y $00000000000^{4}$ ก

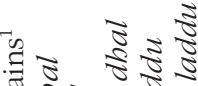


Household utensils were the most used storage medium for mung bean products, except for sweets and snacks, which were stored in plastic bags. Mung bean grains were mainly kept in gunny bags at farmers' and wholesale merchants' level, while plastic packaging was common at retail level. Urban household consumers used metal utensils to store the grains. Rural household consumers also used mud-baked and clay-paper mash based utensils for mung bean grain storage. Most of the products were reported to be available in urban as well as rural areas except for whole laddu, which is typically a rural, home-made product. Only old rural ladies know how to prepare it. Dhals like whole dhal and split dhal, sweets like burfi, halwa, and laddu and snacks like namkeen, papad, pakore, and bhalle were the most liked products, whereas dehulled dhal and khichadi were not liked by consumers.

Consumers wanted halwa and snacks like namkeen, pakore, and bhalle to be present in ready-to-eat or ready-to-cook form. Sweets like dehulled laddu, burfi, halwa, and snacks like namkeen and papad were purchased from retails shops. Dhals, khichadi, and ankurit dhal were said to be household products, whereas snacks like pakore and bhalle were purchased from street vendors. Whole mung bean grains were usually purchased from whole sale or retail shops. In general, dhals were reported to be household products and sweets commercial products. Snacks were considered to be both commercial and household products.

\section{Consumer Perception of Quality}

The interview data depicting consumer perception of mung bean and its derived products are given in table 2. The interviews demonstrated that consumers are aware of the safety of most of the products and that they considered dhals, sweets, snacks, wadi, khichadi and ankurit dhal to be safe for consumption. Pakore and bhalle were considered as moderately safe or unsafe. Consumers considered dhals, wadi, halwa, khichadi, and ankurit dhal to be healthy. Dehulled dhal, khichadi, and ankurit dhal are easily digested foods according to the respondents. Halwa and whole laddu were said to be consumed to increase body weight. They are considered good for growing children to gain strength. Most of the consumers judged the quality of the products on the basis of sensory characteristics, whereas for snacks the location of processing was also considered. Sensory quality was the key reason for the consumption of most of the products, but dehulled dhal, whole laddu, dehulled laddu, halwa, wadi, khichadi, and ankurit dhal were also consumed because of perceived health promoting properties. The most important sensory parameters for the various products as perceived by consumers were consistency (mung bean dhals), color, texture and taste ( halwa), taste and texture (laddu, papad, and namkeen), texture (bhalle and wadi), consistency (kbichadi) and appearance and texture (ankurit dhal). 


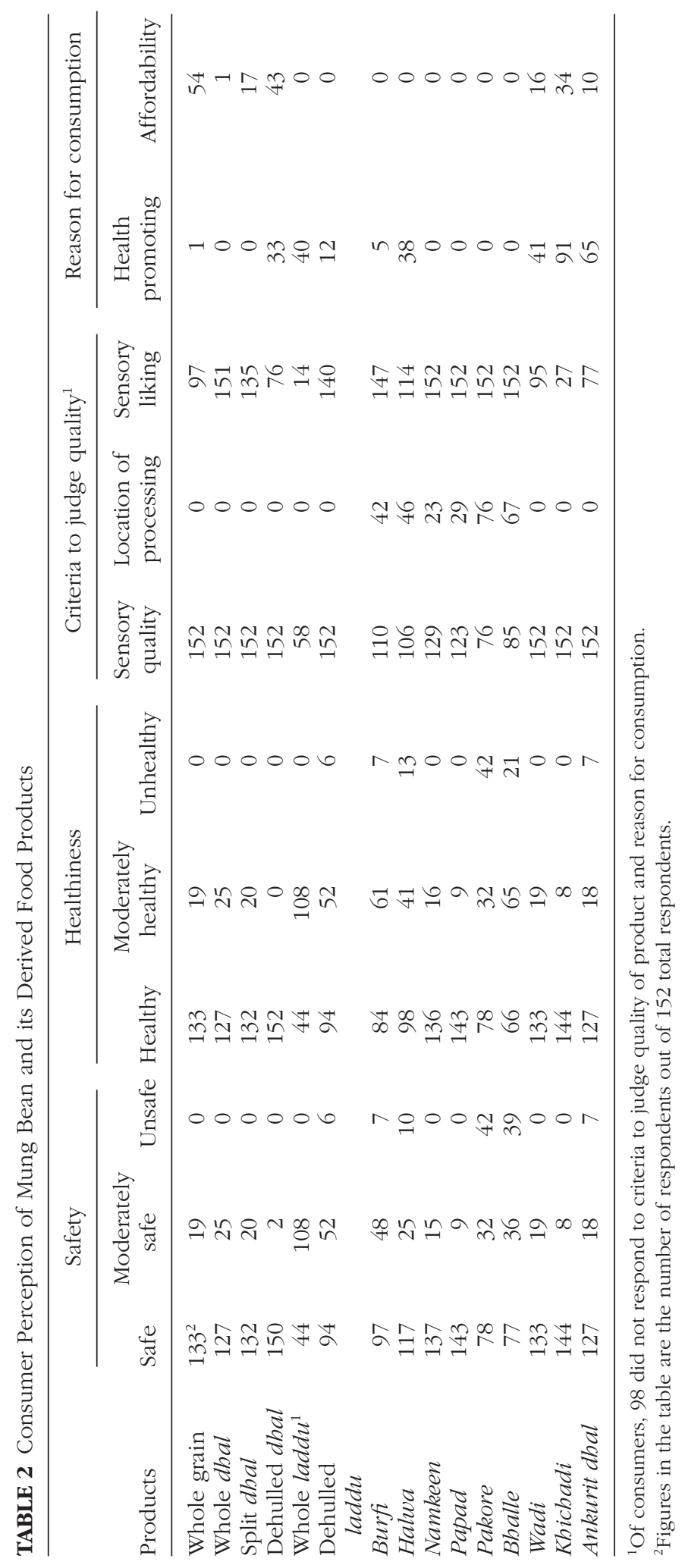


The results of the free word association test showed similar perceptions among the mung bean consumers as the interviews. From the free word association tests, ten response categories were identified for the mung bean and different derived products (table 3). These categories were found to significantly determine the consumer perception of quality of mung bean products. Consumers responded more to three types of dhals, halwa, burfi, khichadi, and bhalle compared to other products. In terms of the response categories, which were the focus of the research, the majority of the consumers associated mung bean and its derived products with sensory liking, which accounted for $32 \%$ of all the associated words. After sensory liking, "positive health effects" was the next most important response category indicating consumers perception towards mung bean products. Overall, sensory disliking, positive health effects, negative health effects, affordability, expensiveness, easy to get, difficult to get, easy processing and difficult processing accounted for $12 \%, 17 \%, 11 \%, 8 \%, 9 \%, 2 \%, 2 \%, 4 \%$, and $4 \%$ of the total responses, respectively.

Correspondence analysis between mung bean products and response categories showed that certain response categories were more strongly associated with specific products $\left(\chi^{2}=1537.5, p<.0005\right)$. Four clear, closely related clusters were identified (figure 1). Cluster one shows the association of dehulled dhal with positive health effects and convenience (easy processing). The second cluster indicates sensory disliking and affordability as the response categories, which are closely associated with wadi and khichadi. Khichadi and wadi are strongly associated with sensory disliking but moderately with affordability. The third cluster contains whole laddu and difficult to get, but the association between them is weak. This cluster is weakly associated with the other three clusters. In the fourth cluster, which is also the largest, there are many products and response characteristics. The majority of the products in this cluster are sweets and snacks. This cluster includes sensory liking, negative health effects, and expensive as the response characteristics; and pakore, bhalle, namkeen, burfi, balwa, ankurit dhal, dehulled laddu, and whole dhal as products and raw mung bean. Bhalle and burfi are more strongly associated with negative health effects, whereas pakore, namkeen, papad, burfi, halwa, and dehusked laddu were strongly associated with sensory liking.

\section{Consumer Dietary Practices}

The interview data depicting consumer practices for consumption of mung bean and its derived products are given in table 4. Dhals, khichadi, and wadi were consumed by the respondents mainly at lunch and dinner, whereas namkeen and pakore were consumed mainly at tea time. Dhals, sweets, khichadi, ankurit dhal, and wadi were consumed at home, whereas bhalle was reported to be a street food. On the contrary, there was no fixed place 


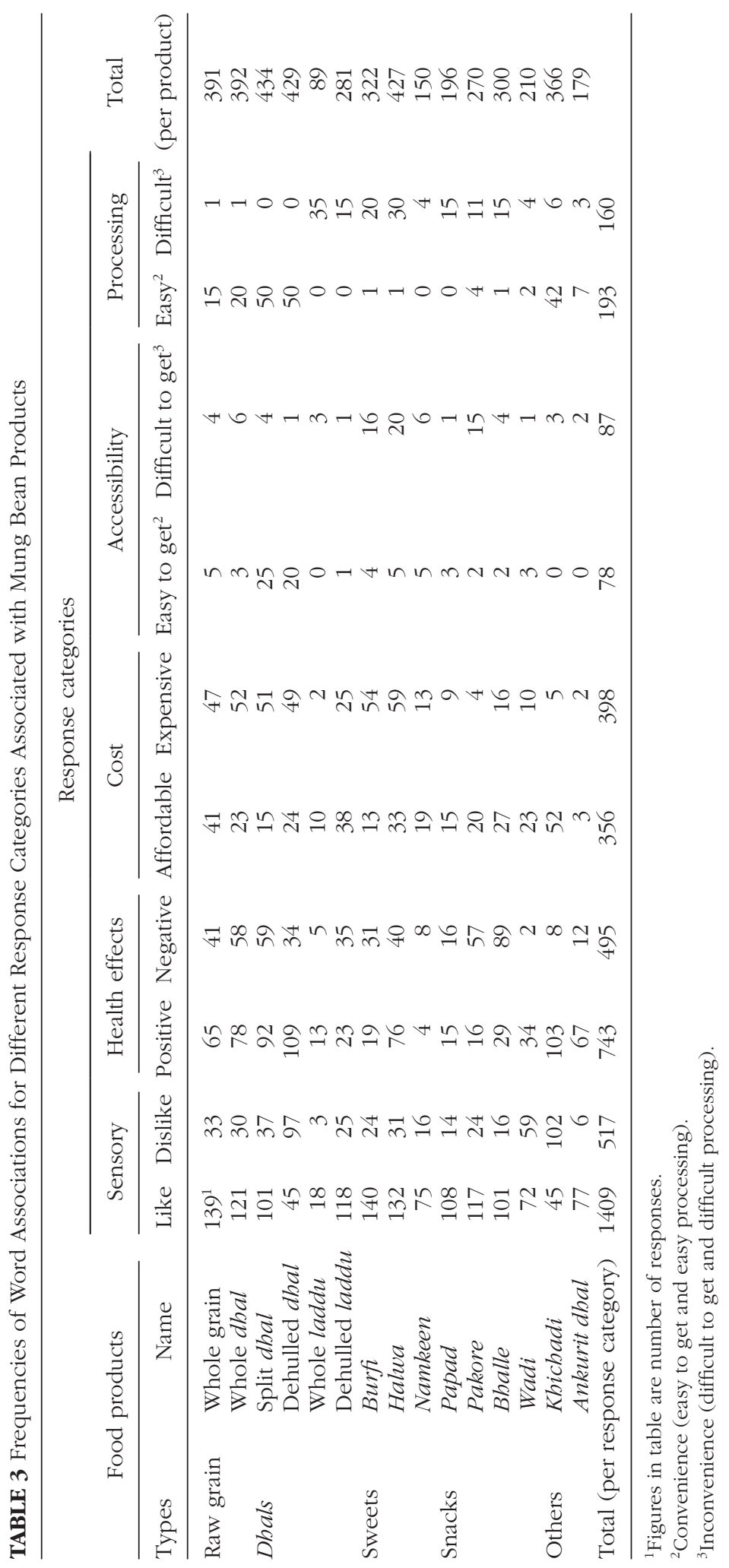




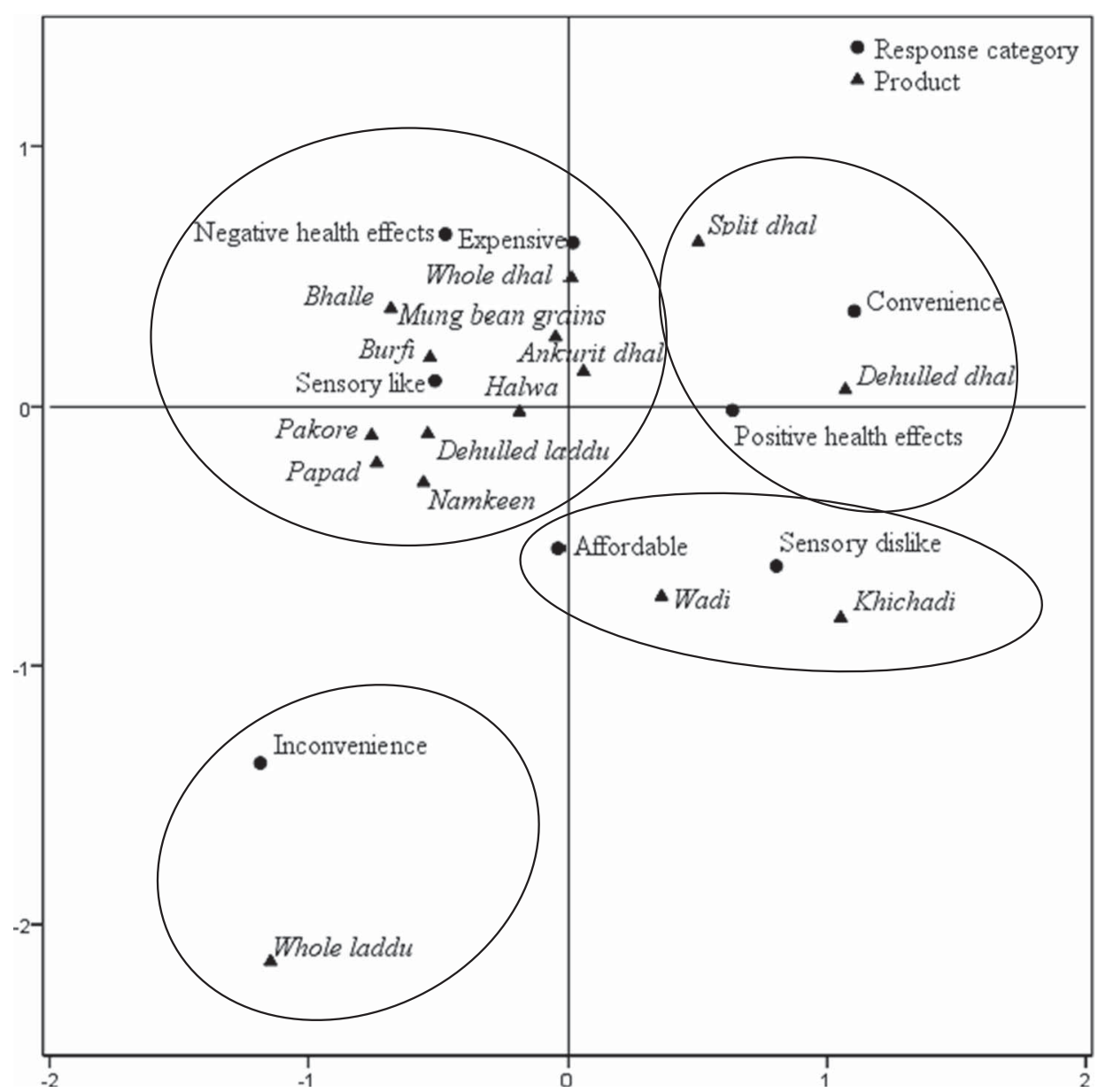

FIGURE 1 Correspondence analysis of response categories associated with mung bean and its derived products.

for the consumption of namkeen, papad and pakore. Dhals, halwa, pakore, and wadi were said to be consumed warm, whereas dehulled laddu, whole laddu, papad, namkeen, bhalle, and ankurit dhal were consumed cold. Per $100 \mathrm{~g}$ edible food, mung bean dishes observed supplied $12.0 \%-59.5 \%$ of protein, $5.2 \%-45.6 \%$ of iron, and $1.1 \%-7.1 \%$ of calcium of Recommended Dietary Allowance for Indian children. The ranges mentioned are related to ingredients and preparation method used for each of the food types.

Mung bean products were consumed in different seasons; sweets were only seasonally consumed, whereas dhals and khichadi were consumed weekly or monthly by most consumers. Low frequency of consumption of legume is in line with results previously published (Arlappa et al. 2010). Mung bean snacks were consumed at least once per month or seasonally. 


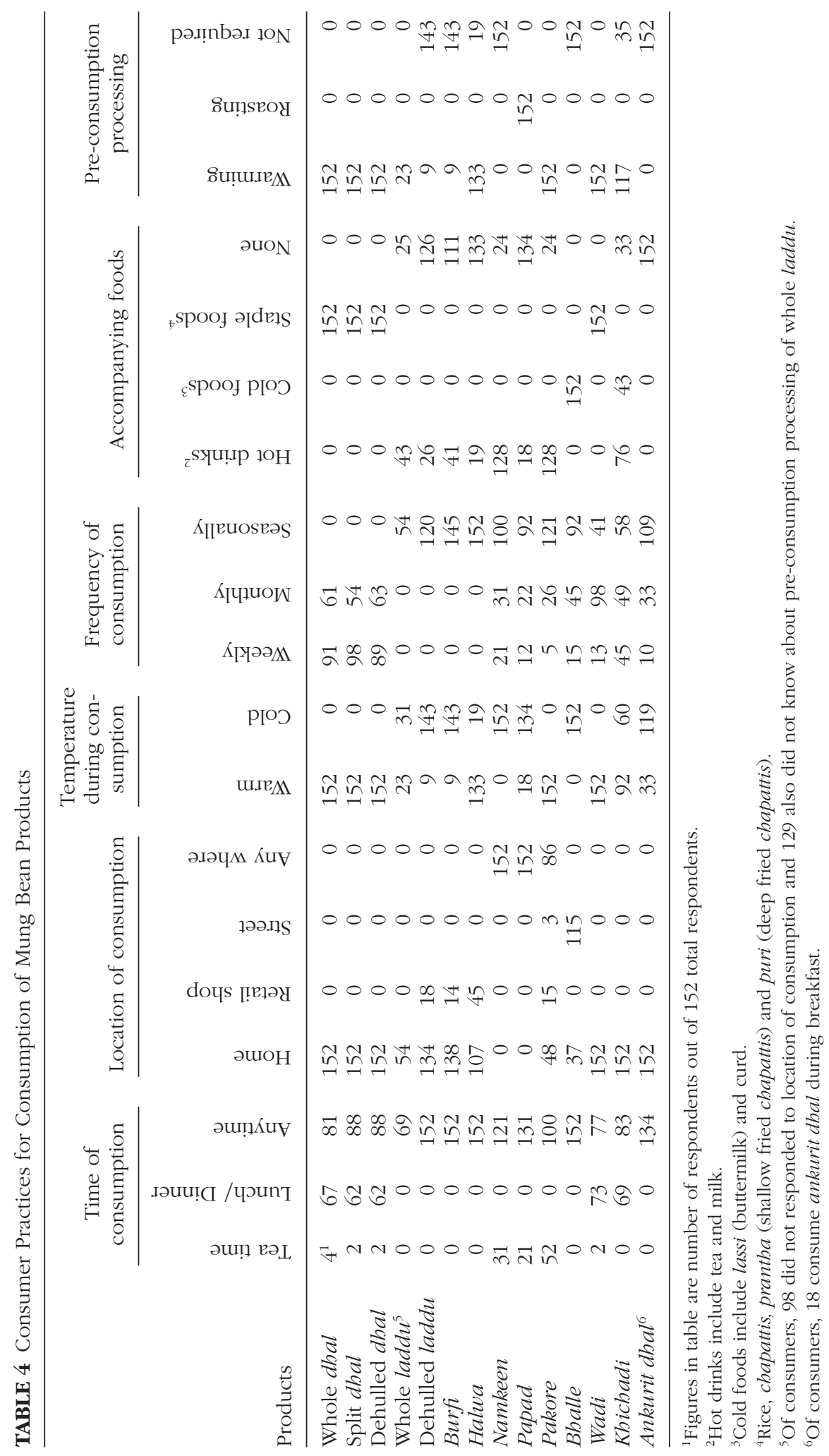


Sweets and snacks were consumed with hot drinks like tea and coffee. Bhalle and kbichadi are the only two products that were consumed with cold food products like curd and lassi (buttermilk). Dhals and wadi were consumed with staple products like rice, chapatti, and parantha (shallow fried chapatti). There is no typical pre-consumption processing required except warming for dhals, halwa, wadi, and khichadi and flame roasting for papad.

\section{DISCUSSION}

Consumer Awareness and Preferences for Mung Bean and its Derived Products

The limited awareness of consumers about mung bean varieties used in the preparation of products shows its insignificance for product quality at household level. This implies that the household products can be prepared using any of the frequently used varieties without a significant change in product specific characteristics. On the contrary, the preference of processors for specific varieties indicates that the quality of commercial products is related to the type of mung bean variety used. To date, no research has been conducted that explains the varietal effect on the quality of mung bean products. Although hybrid varieties were found to be better-yielding than locally established ones, their content of macro- and micro-nutrients was not statistically different (data not shown).

The restricted knowledge of consumers with respect to whole laddu, as compared to other products, indicates that this food is less important in the daily consumption pattern. Processing knowledge seems to have a significant role in consumer choice. Processing of sweets and snacks is difficult and lengthy and thus limits their processing knowledge to specialised processors. This may be the reason why these products are commercial products rather than being part of household dishes.

Preference for consumption of the various mung bean products differed from their consumption practices. Notably, the preference for khichadi was found to be lowest in sheer contrast to its consumption frequency, which was much higher than that of the most preferred products like halwa and laddu. There are socioeconomic and psychological factors that could explain the lower preference for kbichadi and dehulled dhal and the higher preference for halwa and laddu. Khichadi and dehulled dhal are considered as food for diseased people as they are recommended by doctors for their good digestibility. The costs of laddu and halwa are much higher than that of khichadi and dhal. Moreover, halwa and laddu, being seasonal and commercial products, are not available throughout the year. Consumers are not able to purchase them often and thus consume khichadi and dhal frequently. 
Convenience is another essential factor indicated by consumers, which therefore has an impact on the potential of a product to significantly contribute to the nutritional status of its consumers. In this respect, while keeping mid-day meal in mind it would seem that sweets and snacks are perfect as there is no fixed time for their consumption. However, sweets and snacks are prepared by difficult and lengthy processing, which affects the convenience of their use in a negative way. Technological improvements in these products to make them available in ready-to-eat form are a prerequisite to make them more widely available. Until then, their potential as a food to improve the nutritional status is restricted.

\section{Consumer Perception}

Sensory attributes of the various mung bean products were found to play an important role in the consumer perception of product quality. Consumer perception of the safety of the mung bean products showed that household products are considered to be safer than commercially available products like sweets and snacks. Dhals are household products and therefore consumers are aware of the way of processing and thus trust them to be safe to eat. Sweets were considered to be moderately healthy due to their high fat content. Pakore and bhalle were considered as unhealthy due to their availability in the street, which is associated with low quality processing and unhygienic conditions. This is also evident from the fact that for snacks the location of processing is thought to be one of the criteria to judge the quality of product. However, most of the consumers judge the quality of the products on the basis of sensory characteristics, which shows this to be the main indicator of quality. As street foods are perceived to be rather unsafe and poor quality products, there is potential for technological developments to make these products available in ready-to-cook or ready-to-eat form as consumers show a high preference for them.

\section{Consumer Dietary Practices}

Interactions between consumer knowledge, perception, preferences and socioeconomic circumstances compels consumers to adopt certain dietary practices (Sorensen et al. 2003; Dewettinck et al. 2008). Moreover, dietary practices are one of the key factors deciding the nutritional status of an individual. For instance, vegetarian dietary practices have drawbacks associated with it in terms of mineral nutrition compared to non-vegetarian dietary practices. The bioavailability of minerals such as iron from plant foods is considerably lower than from meats because of the uptake inhibitory effect of phytic acid and polyphenols occurring in plant foods such as cereals (Nout 2009) and pulses such as mung bean, in contrast to haem-iron, which is easily digestible (Hurrell and Reddy 2003; Bohn et al. 2004). 
Similarly, mung bean dietary practices seem to have few drawbacks, and thus provide technological options for improvement. Mung bean consumer's preferences indicated that most of the consumption habits have been developed and evolved with social experiences but still some consumption related constraints exist, which were estimated to have major nutritional and health impact leading to public health problems like mineral deficiency.

Frequency of consumption is a decisive factor for the extent in which a food contributes towards nutrition. Dhals, namkeen, and khichadi have the highest frequency of consumption among the investigated mung bean foods. Yet their frequency of consumption may seem low in a vegetarian population, which depends on legumes for its protein source. However, consumers have other legumes like chick pea, pigeon pea as an alternative for consumption (Khetarpaul and Khetarpaul 2006). Thus, this possibility of preparing dhals with different legumes restricts daily mung bean dhal consumption. But, compared to mung bean sweets and snacks, the higher frequency of consumption of dhals and khichadi shows their potential to satisfy hunger and their larger contribution towards overall nutrition. Therefore, the consumption of dhals indicates their potential for being a vehicle to improve the nutrition status of the population.

Apart from the frequency of consumption and convenience, accompanying products also influence the potential of food products to contribute to the nutritional status of its users. Consumers eat dhal with many variations in its recipe. One of the important variations is spinach mung bean dhal. This product containing spinach might not be a good source of mineral nutrition as oxalates in spinach might hinder mineral absorption in the human intestine (Gupta et al. 2006). Similarly, results indicate that snacks are consumed with hot drinks like tea and coffee. This dietary habit shows ineffective use of total minerals present in snacks, as tea contains tannins that potentially bind with minerals, thereby reducing their bioavailability (Temme and Van Hoydonck 2002). However, another mung bean dietary pattern in which consumers add lemon juice to dhals prior to consumption indicates a promising combination as ascorbic acid in lemon enhances iron absorption through solubilization by reduction of ferric iron to ferrous iron (Fidler et al. 2003). The combination of these products is expected to improve nutrient bioavailability. From a nutritional point of view, combinations of foods high in sulphur-containing amino acids with mung bean are advisable, as it lacks methionine (Mendoza et al. 2001). Consumption of dhals with cereal products like Indian bread and rice indicate potential combination in terms of amino acid nutrition. This consumption pattern provides balanced amount of lysine, a limiting amino acid in cereals and methionine, limiting amino acid in legumes. Cereal based mung bean products like khichadi and dhal parantha (Indian bread prepared with cooked dhal and wheat flour) are considered good in terms of balanced amino acid intake.

Accompanying food seems to have significant impact on the overall nutritional potential of mung bean foods. Therefore research on the effects 
of mung bean product combinations on the overall nutritional profile of dishes is advocated.

\section{Innovation Potential}

Single or few options in diet lead to malnutrition, but despite diverse mung bean food products to choose from, the adverse health implications persists (Pathak and Singh 2011). Redesigning traditional foods for combating household nutritional insecurity requires careful selection of food products. Several mung bean products seem to offer potential as vehicles to alleviate malnutrition on the basis of nutritional composition (e.g., mineral contents and their bioavailability), consumer characteristics (i.e., knowledge, perception, preference and practices) and socioeconomic circumstances. Factors like affordability, ease of processing, storage methods used, product procurement, time of consumption, temperature during consumption and pre-consumption requirement govern the accessibility aspect of the mung bean products. However, perceived sensory liking, positive health perception, nutrient content, food preference, frequency of consumption, and accompanying food products determine the nutritional contribution of the products to the overall food intake. These factors interact with each other and lead to final food choice. In case of mung bean foods, the consumers prefer products with high sensory quality. Thus, they prefer to consume sweets like halwa and laddu, but perceive khichadi as healthy. However, consumers choose dhals for day-to-day consumption. This indicates that in certain circumstances food choice is influenced more by socioeconomic restrictions then by consumer perception and preferences (Hoefling and Strack 2010).

In order to get a holistic view of these influences on food choice, the selected factors were ranked and used to outline different scenarios (table 5). These scenarios provide insight in the options for using mung bean foods to alleviate malnutrition while staying as close as possible to local food uses and preferences. All products were ranked on the basis of data from tables 1-4 that present different aspects of mung bean consumption. Table 5 shows that dhals are the most promising products but also that different factors favor different products. Increasing the weight for certain factors might give different ranking results. This is relevant because certain factors can be adjusted by dedicated technological research, i.e. they can be improved to match consumer wants. The possible flexible factors that determine the innovation potential are nutrient content (nutritional scenario-1), frequency of consumption (consumption scenario-2) and accompanying products (accompanying food scenario-3) as indicated in table 5. Nutritional scenario is calculated by giving extra weight to the intake of protein, iron and zinc per portion of the mung bean food (data not shown). Consumption scenario is calculated by giving extra weight to the frequency of consumption of each mung bean products. Similarly, accompanying food scenario is calculated by giving extra 


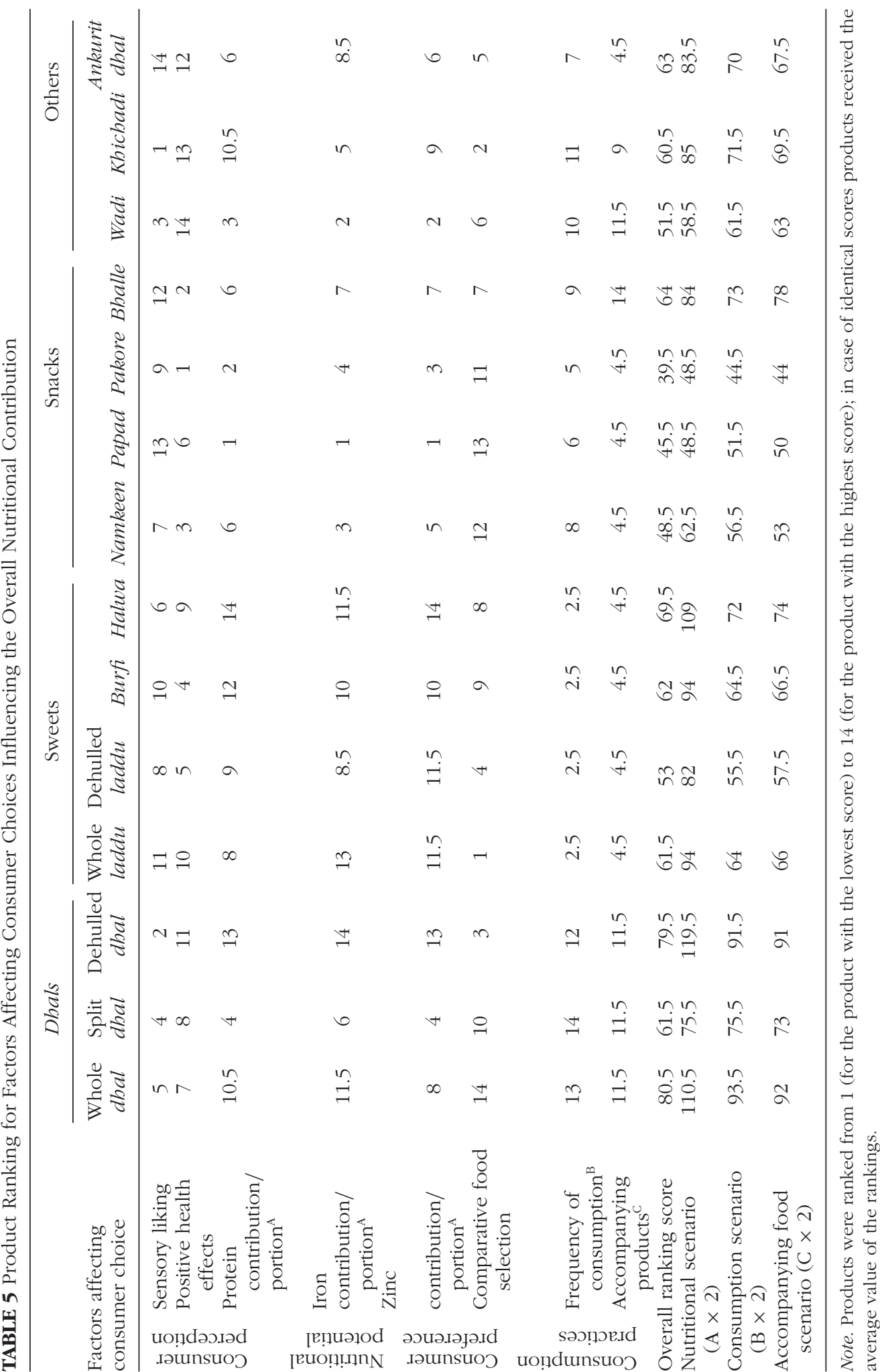


weight to accompanying foods with potential to improve nutritional quality of foods. Interestingly, all scenarios lead to the same conclusion, namely that dhals are the most promising product.

Dhals are valuable because they are highly nutritious and deliver sustenance while simultaneously being easy to digest and process. Dhals also contribute significantly in terms of protein, iron and zinc nutrition. Further improvements can be made by breeding for varieties that have better characteristics from a nutritional point of view (Dahiya et al. 2013a). Compared to other mung bean products, dhals are also relatively cheap, easily available and have convenient processing. Moreover, reformulation of their recipes offer options for nutritional improvement by incorporating nutrient-rich locally available ingredients like vegetables fruits and spices (Shanmugasundaram 2007). Few examples of this approach are provided by supplementing mung bean based dishes used in a school feeding program in India (Sathya et al. 2002; Vijayalakshmi et al. 2008). The accompanying foods of dhals (rice, chapattis) are low in antinutritional factors that might reduce their nutrient availability. Processing methods of dhals involve only cooking and soaking, thus providing potential for incorporating other nutrient enhancing processing methods like fermentation or germination to prepare these products with improved or minimal change in sensory parameters. Poor sensory attribute in dehulled dhal should be improved by enriching with local vegetables. Therefore, research in nutritional enhancement of dhals is required.

Apart from product development, redesigning traditional foods is also required at consumption level. As different accompanying foods might give different nutritional output, it is important to select accompanying foods with care. Therefore, social extension programs like self-help groups can play their role in spreading the awareness of proper dietary habits for harnessing proper nutritional output of mung bean foods. Food-based dietary guidelines are required to be designed to ensure proper awareness through extension activities (Brown et al. 2011).

Thus, when deciding about the choice of any food product as a vehicle to alleviate malnutrition among relevant populations, we advocate not merely relying on sensory appreciated products but using an approach that takes account of other factors that govern food choice as well. Moreover, indigenous mung bean consumption possesses different technological and behavioral constraints for which multi-disciplinary research and development can be utilized for proper rectification or improvisation.

In conclusion, four groups of closely related products and perceived quality were revealed. The largest group comprised sweets and snacks, which were associated with unhealthiness, expensiveness and sensory liking. Another group consisted of split dhals associated with convenience and healthiness. It appeared that under different circumstances food choices vary and are influenced more by socioeconomic restrictions then by consumer 
perception and preferences. Our major recommendation is to focus on dhals as the most promising food for further innovation.

\section{FUNDING}

We gratefully acknowledge the financial support from the Department of Biotechnology, Ministry of Science and Technology, Government of India, from Wageningen University through the Interdisciplinary Research and Education Fund (INREF) via the TELFUN programme and from the International Foundation of Science (IFS) (Grant No. - A E/21294).

\section{REFERENCES}

Arlappa, N., .A. Laxmaiah, N. Balakrishna, and G. N. V. Brahmam. 2010. Consumption pattern of pulses, vegetables and nutrients among rural population in India. African Journal of Food Science 4:668-675.

Bohn, T., L. Davidsson, T. Walczyk, and R. F. Hurrell. 2004. Phytic acid added to white-wheat bread inhibits fractional apparent magnesium absorption in humans. American Journal of Clinical Nutrition 79:418-423.

Brown, K. A., L. Timotijevic, J. Barnett, R. Shepherd, L. Lahteenmaki, and M. M. Raats. 2011. A review of consumer awareness, understanding and use of food-based dietary guidelines. British Journal of Nutrition 106:15-26.

Chadare, F. J., J. D. Hounhouigan, A. R. Linnemann, M. J. R. Nout, and M. A. J. S. van Boekel. 2008. Indigenous knowledge and processing of Adansonia digitata L. food products in Benin. Ecology of Food and Nutrition 47:338-362.

Dagnelie, P. 1998. Statistique théorique et appliquée: Inference statistique à une et à deux dimensions. Brussels, Belgium: De Boeck and Larcier S.A.

Dahiya, P. K., A. R. Linnemann, M. J. R. Nout, M. A. J. S. van Boekel, and R. B. Grewal. 2013a. Nutrient composition of selected newly bred and established mung bean varieties. LWT - Food Science and Technology 54:249-256.

Dahiya, P. K., A. R. Linnemann, M. J. R. Nout, M. A. J. S. van Boekel, N. Khetarpaul, R. B. Grewal. 2013b. Mung bean: Technological and nutritional potential. Critical Reviews in Food Science and Nutrition. Taylor and Francis Online, September 12. doi:10.1080/10408398.2012.671202.

Dewettinck, K., F. Van Bockstaele, B. Kuhne, D. Van de Walle, T. M. Courtens, and X. Gellynck. 2008. Nutritional value of bread: Influence of processing, food interaction and consumer perception. Journal of Cereal Science 48:243-257.

Fidler, M. C., L. Davidsson, C. Zeder, T. Walczyck, and R. F. Hurrell. 2003. Iron absorption from ferrous fumarate in adult women is influenced by ascorbic acid but not by $\mathrm{Na}_{2}$ EDTA. British Journal of Nutrition 90:1081-1085.

Giampieri-Deutsch, P. 2012. Perception, conscious and unconscious processes. In Sensory perception, ed. F. Barth, P. Giampieri-Deutsch, and H.-D. Klein, 245-264. Vienna: Springer. 
Guerrero, L., A. Claret, W. Verbeke, G. Enderli, S. Zakowska-Biemans, F. Vanhonacker, S. Issanchou, et al. 2010. Perception of traditional food products in six European regions using free word association. Food Quality and Preference 21:225-233.

Gupta, S., A. Lakshmi, and J. Prakash. 2006. In vitro bioavailability of calcium and iron from selected green leafy vegetables. Journal of the Science of Food and Agriculture 86:2147-2152.

Hoefling, A., and F. Strack. 2010. Hunger induced changes in food choice: When beggars cannot be choosers even if they are allowed to choose. Appetite 54:603-606.

Hurrell, R., and M. Reddy. 2003. Degradation of phytic acid in cereal porridges improves iron absorption by human subjects. American Journal of Clinical Nutrition 77:1213-1219.

Khetarpaul, M., and N. Khetarpaul. 2006. Food consumption pattern of Indian rural preschool children (four to five years). British Food Journal 108:127-140.

Linnemann, A. R., M. Benner, R. Verkerk, and M. A. J. S. van Boekel. 2006. Consumerdriven food product development. Trends in Food Science \& Technology 17:184-190.

Mendoza, E. M. T., M. Adachi, A. E. N. Bernardo, and S. Utsumi. 2001. Mungbean [Vigna radiata (L.) Wilczek] globulins: Purification and characterization. Journal of Agricultural and Food Chemistry 49:1552-1558.

Nout, M. J. R. 2009. Rich nutrition from the poorest: Cereal fermentations in Africa and Asia. Food Microbiology 26:685-692.

Pathak, P. K. and A. Singh. 2011. Trends in malnutrition among children in India: Growing inequalities across different economic groups. Social Science E Medicine 73:576-585.

Quaye, W., K. Adofo, Y. E. Madode, and A.-R. Abizari. 2009. Exploratory and multidisciplinary survey of the cowpea network in Tolon-Kumbungu district of Ghana: A food sovereignty perspective. African Journal of Agricultural Research 4:311-320.

Ruel, M. T., and C. E. Levin. 2002. Food-based approaches for alleviating micronutrient malnutrition: An overview. Journal of Crop Production 6:31-53.

Sathya, R., M. Amirthaveni, and P. Vijayalakshmi. 2002. Enhancing the bioavailability of iron from mungbean through simple modifications in cooking. Indian Journal of Nutrition and Dietetics 39:45-54.

Shanmugasundaram, S. 2007. Exploit mungbean with value-added products. Acta Horticulturae 752:99-102.

Siró, I., E. Kápolna, B. Kápolna, and A. Lugasi. 2008. Functional food: Product development, marketing and consumer acceptance-a review. Appetite 51:456-467.

Sorensen, L. B., P. Moller, A. Flint, M. Martens, and A. Raben. 2003. Effect of sensory perception of foods on appetite and food intake: A review of studies on humans. International Journal of Obesity 27:1152-1166.

Sourial, N., C. Wolfson, B. Zhu, J. Quail, J. Fletcher, S. Karunananthan, K. BandeenRoche, F. Béland, and H. Bergman. 2010. Correspondence analysis is a useful tool to uncover the relationships among categorical variables. Journal of Clinical Epidemiology 63:638-646. 
Temme, E., and P. G. A. Van Hoydonck. 2002. Tea consumption and iron status. European Journal of Clinical Nutrition 56:379-386.

van Kleef, E., H. C. M. van Trijp, and P. Luning. 2005. Consumer research in the early stages of new product development: A critical review of methods and techniques. Food Quality and Preference 16:181-201.

Vijayalakshmi, P., M. Amirthaveni, C. S. T. Samson, and S. Shanmugasundaram. 2008. Supplementing iron bioavailability enhanced mung bean. Asia Pacific Journal of Clinical Nutrition 17:99-102.

Yang, R. Y., and S. C. S. Tsou. 1998. Mungbean as a potential iron source in south Asian diets. In Proceedings of the International Consultation Workshop on Mung Bean, 152-158. Shanhua, Taiwan: World Vegetable Center. 